Case Report

\title{
Shunt Migration into Scrotum: A Case Report
}

\author{
Muhammad Assad Javed ${ }^{1}$, Niaz Ahmad Khan ${ }^{2}$, Ain-us-Saba², Huda Sana ${ }^{1}$ \\ ${ }^{1}$ Islamabad Medical \& Dental College (IMDC), Islamabad \\ ${ }^{2}$ Pakistan Institute of Medical Sciences (PIMS), Islamabad, Pakistan
}

\begin{abstract}
Ventriculoperitoneal shunting (VPS) is a common procedure involved in the management of hydrocephalus. VP shunt has many inherent complications including obstruction, infection, breakage, and migration of the shunt. The incidence of scrotal shunt migration is around 14\% VPS migration into the scrotum manifests as reducible trans-illuminant scrotal swelling, which is more like hydrocele. Mostly migration occurs into the right hemi-scrotum within the first 6 months of performing a ventriculoperitoneal shunt. Bilateral herniotomy with repositioning of the distal shunt catheter is the treatment of choice.
\end{abstract}

Keywords; Hydrocephalus; Ventriculoperitoneal shunt; Scrotal Migration.

Abbreviations: VPS: Ventriculoperitoneal Shunt. PPV: Patent Processus Vaginalis.

\section{Corresponding Author: Muhammad Assad Javed \\ Assistant Professor Neurosurgery, \\ Akbar Niazi Teaching Hospital \\ Islamabad Medical \& Dental College (IMDC), \\ Islamabad - Pakistan \\ Email: asad.amc@gmail.com}

Date of Submission: 10-09-2020

Date of Revision: 25-04-2021

Date of Online Publishing: 13-06-2021

Date of Print: 30-06-2021

DOI: $10.36552 /$ pjns.v25i2.558

\section{INTRODUCTION}

Ventriculoperitoneal shunting is a common procedure involved in the management of hydrocephalus. The procedure is done in order to redirect the flow of CSF from the ventricles to the peritoneum in Hydrocephalus. ${ }^{1}$ VP shunt has many complications associated with it including proximal or distal catheter obstruction, breakage, and migration of the shunt. Shunt infection is also a very dangerous complication and a major cause of shunt failure.

Possible sites for VPS migration consist of the GIT tract, bladder, abdominal wall, mediastinum, vagina, and scrotum. ${ }^{2}$ Male infants are at risk of shunt migration into the scrotum. The incidence of scrotal migration of shunt is around $14 \%{ }^{3}$ VPS migration into the scrotum manifests as scrotal swelling, which is reducible and trans-illuminant hydrocele and usually occurs through patent processus vaginalis (PPV), a developmental pathway of testicular descent. Most of the migrations are toward the right scrotum. They usually occur within the first 6 months of performing a ventriculoperitoneal shunt. ${ }^{4} 90 \%$ of boys at birth have patent processus vaginalis 
which becomes $50 \%$ at 1 year, $(50-60 \%$ at age 1 year). Increase in abdominal pressure following VP shunt implantation due to in-flow of cerebrospinal fluid may be a causative factor in the prolonged patency of the processus vaginalis. $^{5}$ Bilateral herniotomy with the procedure of repositioning of the shunt tube is one of the treatment approaches.

A case of scrotal migration of VPS in a 5month old male infant was reported.

\section{CASE REPORT}

A 5-month old infant presented with Increasing head size since birth. On examination, the patient had macrocephaly along with sun setting eye signs and bulging anterior fontanelle. OFC was noted to be $54 \mathrm{~cm}$. The rest of the neurological and general examination was unremarkable. MRI brain showed communicating hydrocephalus. Ventriculoperitoneal shunting was done. On $4^{\text {th }}$ post, operative day patient developed right-sided testicular swelling. On examination, the swelling was fluctuant, non-tender, and trans-illuminant.

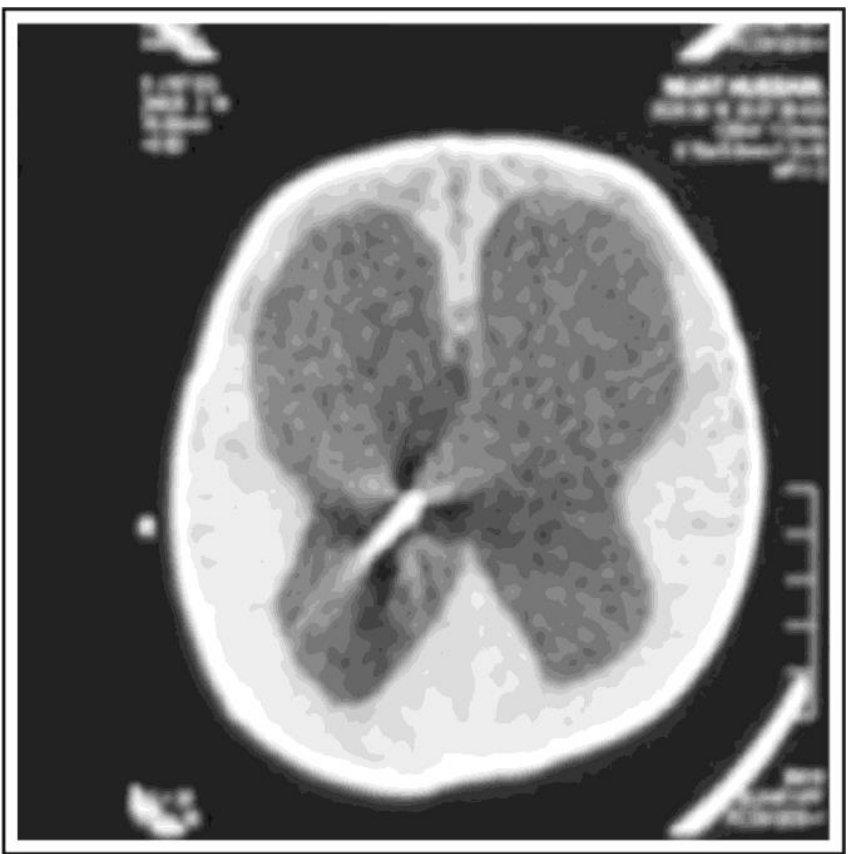

Figure 1: Post OP scan of the patient showing shunt dysfunction.

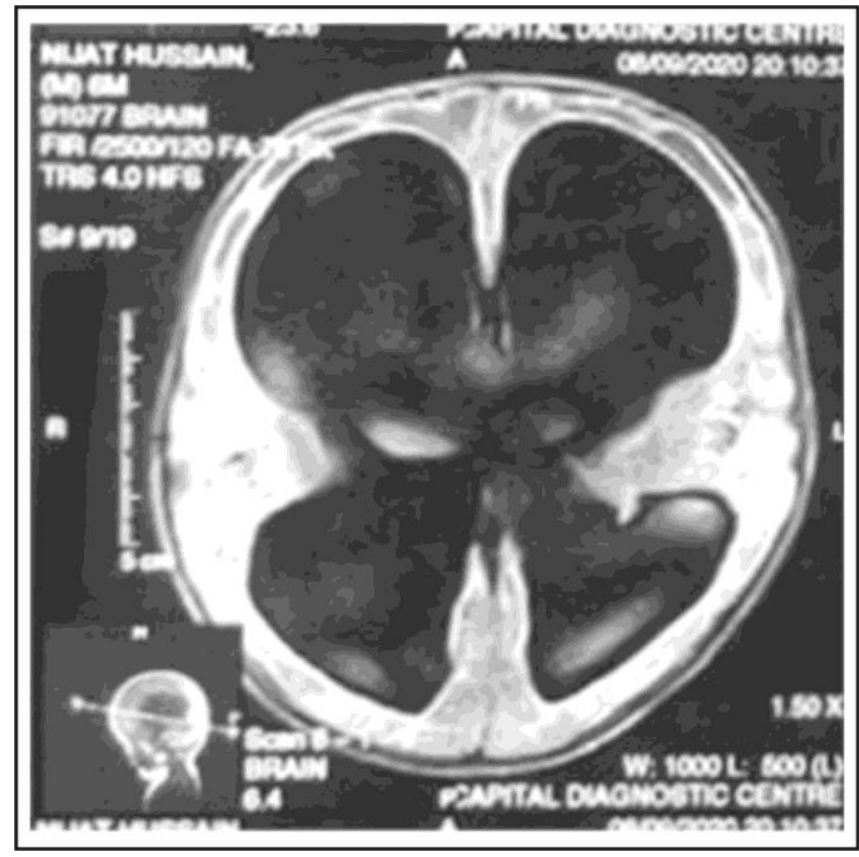

Figure 2: Preop MRI scan of patient's brain showing communicating hydrocephalus.

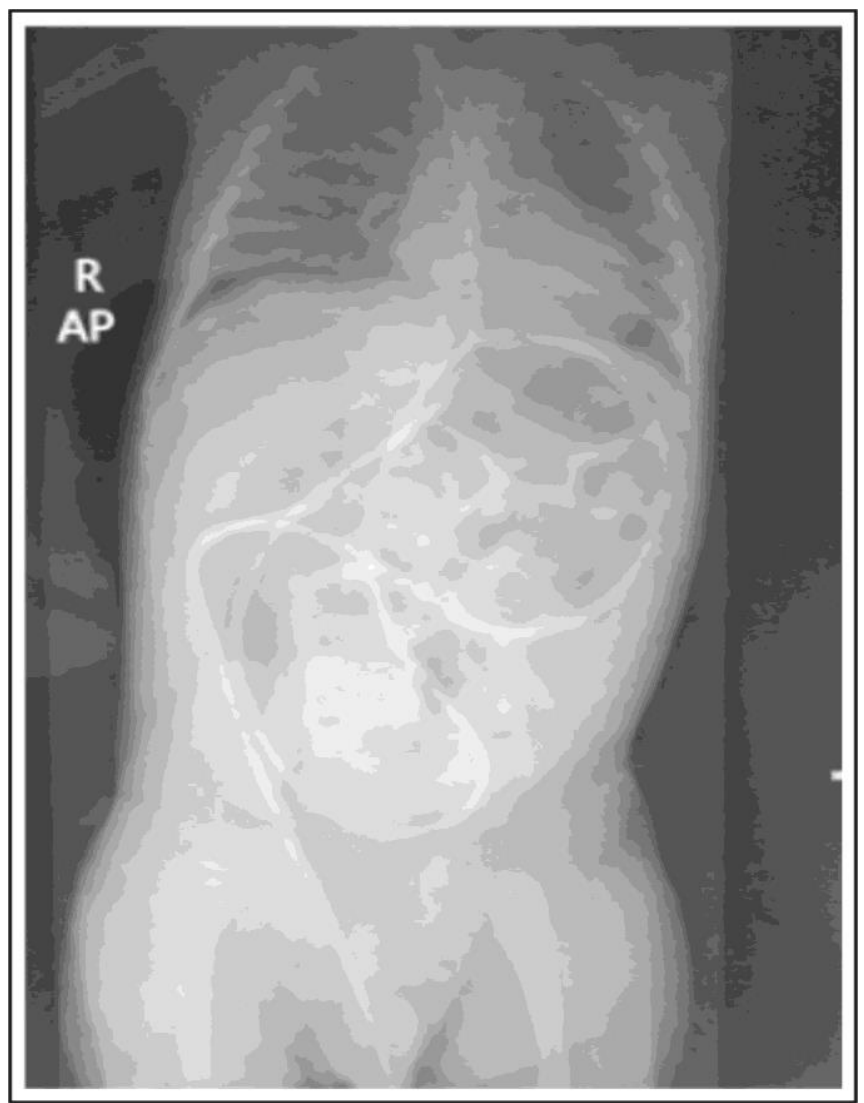

Figure 3: Abdominal x-ray of patient showing migration of VPS tip.

Pak. J. of Neurol. Surg. -2021 - 25 (2): 194-198. 
On Palpation a hard-tubular structure was noted with a normal opposite side. Abdominal x-ray showed distal catheter migration into right hemiscrotum along with right paracolic gutter. Patient also developed signs of raised ICP including vomiting and bulging fontanelle. CT scan showed a normally place ventricular tip with dilated ventricles. Pediatric surgery consultation was done followed by patent processus vaginalis (PPV) ligation and reposition of the shunt into the peritoneal cavity. Postoperatively, the patient recovered well with the settlement of raised ICP signs and symptoms.

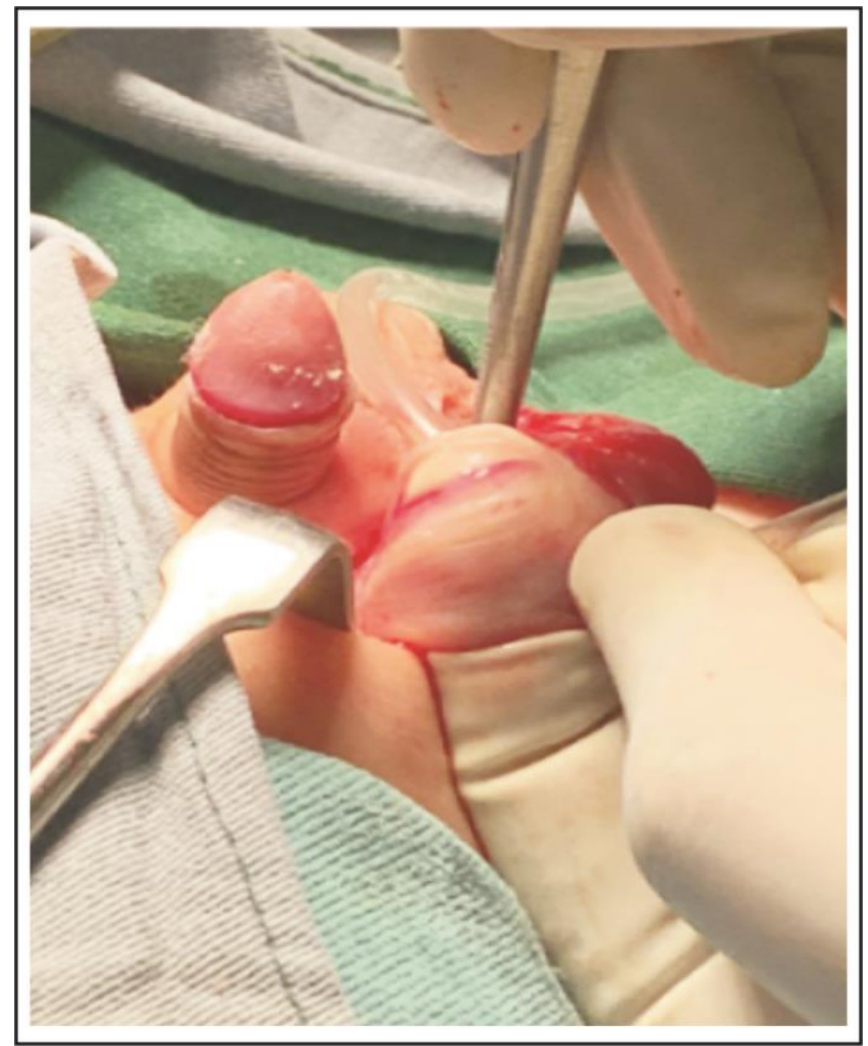

Figure 4: Surgical closure of processus vaginalis and repositioning of shunt into the peritoneal cavity.

\section{DISSCUSION}

Congenital hydrocephalus is a clinical entity in which cerebrospinal fluid starts accumulating inside the ventricular system of the brain. The reported occurrence of congenital hydrocephalus is almost about 0.2-0.5/1000 live births. ${ }^{6}$

The procedure is commonly used for patients with hydrocephalus and it is best known due to the excellent resorptive function of the peritoneum for fluid. This is called ventriculoperitoneal shunting. ${ }^{7}$ Composition of VP shunt is a pressure valve, a ventricular catheter, and a distal peritoneal catheter. The function of the ventricular catheter is to redirect the flow of cerebrospinal fluid from ventricular space into peritoneum via distal end while drainage of fluid is controlled by valves. ${ }^{8}$

Shunt malfunction due to distal catheter migration is an uncommon complication that occurs hours to years after the placement of the shunt system. ${ }^{7}$ Distal shunt catheters can migrate into various organ systems including the gastrointestinal tract, urinary bladder, and chest. ${ }^{9}$ Scrotal shunt migration is a possible but rare site for a shunt to migrate and till now only 10 cases of scrotal shunt migration have been described in the literature. The prevalence of distal catheter scrotal migration is between 3.8 and $16.8 \%$ and $60 \%$ of the distal catheter migration occurs into the right side as in our case. ${ }^{10}$

The first patient with scrotal migration was reported by Ramani et al., in $1974 .^{11}$ The majority ( $n=54$ ) of the patients have been children with only one adult patient being reported by Rehm et al., in $1997 .{ }^{12}$ Even among children, most (84.8\%) of the migrations occur in children $<2$ years of age. There has been only one report of herniation of the shunt through the canal of Nuck in a female infant. ${ }^{13}$ The largest series of 10 patients with an inguinoscrotal migration was by Pandey et al., in 2010.

Various pathophysiologic mechanism scan be responsible for distal catheter migration. Intraabdominal pressure increases after VP shunting firstly due to CSF drained from the ventricle into the abdominal cavity and secondly due to small peritoneal volume to body surface area in young infants.

Failure of the processus vaginalis to close is 
another factor in distal catheter migration into the scrotum. ${ }^{14,15}$ This is normally patent structure in almost $60-70 \%$ of infants of three months while it is about $50-60 \%$ at age of 1 year and $40 \%$ at the age of $2-16$ years. ${ }^{16}$ Increased intraabdominal pressure stops the closing of processus vaginalis and later this helps in shunt herniation. ${ }^{17}$ It is also reported that scrotal shunt migration has an association with the formation of hernias in children (right $-60 \%$, left $-30 \%$, bilateral - $10 \%)^{5}$

The residual peritoneal volume is linearly correlated with the body surface area at approximately $80 \mathrm{ml} / \mathrm{m}^{2}$. Younger children tend to have patent processus vaginalis and smaller peritoneal cavity, so the VP shunt catheter may easily migrate into the scrotum. ${ }^{5}$ Moreover, the inguinal canal is also vertical aligned at this young age and combined with a PPV and raised intraabdominal pressure makes it easier for the distal shunt catheter into the scrotum. ${ }^{18}$

\section{CONCLUSION}

In our case young age along with patent processus vaginalis (PPV) and raised intraabdominal pressure was the possible cause for shunt migration.

\section{REFRENCES}

1. Pudenz R.H. The surgical treatment of hydrocephalus-A historical review. Surg Neurol. 1981; 15 (1): 15-26.

2. Vuyyuru S, Ravuri SR, Tandra VR, Panigrahi MK. Anal extrusion of ventriculo peritoneal shunt tube: Endoscopic removal. J Pediatr Neurosci. 2009; 4: 124-126.197

3. Harischandra LS, Sharma A, Chatterjee S. Shunt migration in ventriculoperitoneal shunting: $A$ comprehensive review of literature. Neurol India, 2019; 67 (1): 85-99.

4. Mohammadi A, Hedayatiasl A, Ghasemi-Rad M. Scrotal migration of a ventriculoperitoneal shunt: a case report and review of literature. Med Ultrason.
2012; 14 (2): 158-160.

5. Kita D, Hayashi Y, Kinoshita M, Ohama K, Hamada J. Scrotal migration of the peritoneal catheter of a ventriculoperitoneal shunt in a 5-year-old male. Case report. Neurol Med Chir (Tokyo). 2010; 50: 1122-1125.

6. Venkataramana NK. Hydrocephalus Indian scenario A review. J Pediatr Neurosci. 2011; 6 (Suppl. 1): S11-S22.

7. Agarwal N, Shukla RM, Agarwal D, Gupta K, Luthra R, Gupta J, et al. Pediatric Ventriculoperitoneal Shunts and their Complications: An Analysis. J Indian Assoc Pediatr Surg. 2017; 22 (3): 155-157. :

8. Paulsen AH, Lundar T, Lindegaard KF. Twenty-year outcome in young adults with childhood hydrocephalus: Assessment of surgical outcome, work participation, and health-related quality of life. J Neurosurg Pediatr. 2010; 6: 527-35.

9. Agarwal T, Pandey S, Niranjan A, Jain V, Mishra S, Agarwal V. Unusual complication of ventriculoperitoneal shunt surgery. J Pediatr Neurosci. 2009; 4 (2): 122-123. -

10. Karaosmanoglu D, Metin $Y$, Akata D, Haliloglu M. An Unusual Cause of Hydrocele: Malpositioned Ventriculoperitoneal Shunt in the Scrotum. J Ultrasound Med. 2008; 27: 159-60.

11. Ramani PS. Extrusion of abdominal catheter of ventriculoperitoneal shunt into the scrotum. J Neurosurg. 1974; 40: 772-3.

12. Rehm A, Bannister CM, Victoratos G. Scrotal perforation by a ventriculoperitoneal shunt. $\mathrm{Br} J$ Neurosurg. 1997; 11: 443-4.

13. Yuksel KZ, Senoglu $M$, Yuksel M, Ozkan KU. Hydrocele of the canal of Nuck as a result of a rare ventriculoperitoneal shunt complication. Pediatr Neurosurg. 2006; 42: 193-6.

14. Kandasamy J, Jenkinson MD, Mallucci CL. Contemporary management and recent advances in paediatric hydrocephalus. BMJ. 2011; 343: d4191.

15. Paff $M$, Alexandru-Abrams $D$, Muhonen $M$, Loudon W. Ventriculoperitoneal shunt complications: A review. Interdisciplinary Neurosurgery, 2018; 13: 66-70.

16. Sarangi GS, Mohanty S, Rout SS. Late onset scrotal 
migration of the distal catheter of a ventriculoperitoneal shunt in a 4 -year-old male with post meningitic hydrocephalus-a case report and review of literature. International Surgery Journal, 2016; 3 (1): 390-3.

17. Bawa M, Garge S, Garg R, Narasimha Rao KL. Scrotal migration of tubing: An unusual complication after ventriculo-peritoneal shunt. Asian J Neurosurg. 2017; 12 (4): 738-740. doi:10.4103/1793- 5482.215783.

18. Ho CC, Jamaludin WJ, Goh EH, Singam P, Zain-udDin ZM. Scrotal mass: a rare complication of ventriculoperitoneal shunt. Acta Medica (Hradec Kralove). 2011; 54 (2): 81-82.

\section{Additional Information}

Disclosures: Authors report no conflict of interest.

Ethical Review Board Approval: The study was conformed to the ethical review board requirements.

Human Subjects: Consent was obtained by the patient in this study.

Conflicts of Interest:

In compliance with the ICMJE uniform disclosure form, all authors declare the following:

Financial Relationships: All authors have declared that they have no financial relationships at present or within the previous three years with any organizations that might have an interest in the submitted work.

Other Relationships: All authors have declared that there are no other relationships or activities that could appear to have influenced the submitted work.

\section{AUTHORS CONTRIBUTIONS}

\begin{tabular}{|l|l|l|}
\hline Sr.\# & Author's Full Name & Intellectual Contribution to Paper in Terms of: \\
\hline 1. & Muhammad Assad Javed & Study design, methodology, paper writing and data calculations. \\
\hline 2. & Niaz Ahmad Khan & Data collection and calculations. \\
\hline 3. & Ain-us-Saba & Analysis of data and interpretation of results etc. \\
\hline 4. & Huda Sana & Literature review and manuscript writing. \\
\hline
\end{tabular}

